\title{
Preparing Transit in the Advent of Automated Vehicles: A Focus-group Study in the Twin Cities
}

\author{
Xinyu Wu ${ }^{1}$, Frank Douma ${ }^{1}$ (D), Jason Cao $^{1}$ (D) ${ }^{\text {, }}$, Erika Shepard ${ }^{1}$ (D) \\ 1 University of Minnesota-Twin Cities (MN) \\ Keywords: environmental justice, driverless vehicle, transit, equity, vehicle automation \\ https://doi.org/10.32866/001c.17872
}

\section{Findings}

The proliferation of automated vehicles (AVs) will bring substantial changes to the transport system. This study illustrates planners' understanding of the potential impacts of AVs on transit and social equity. A focus group discussion of planners from governments and transit agencies in the Twin Cities shows that $\mathrm{AVs}$ may bring both challenges and opportunities to the transit system.

Policymakers need to take actions (such as securing funding sources, developing automated transit, using AVs for flexible services) to ensure the quality of transit service and regulate unoccupied $A V$ s. However, social equity has yet to become a centerpiece in planners' discussion.

\section{Research questions}

Automated vehicles (AVs) are expected to disrupt the transit system in the future. Some argue that AVs have the potential to supplement transit, while others believe that the proliferation of AVs will render transit obsolete (Lutin 2018; Wiseman 2018). In any case, AVs will affect the well-being of transitdependent people. However, the equity impact of $\mathrm{AVs}$ is under-discussed in the literature (Cohen, Shirazi, and Curtis 2017; Cohn et al. 2019). Filling this gap is essential to understanding the implications of $\mathrm{AVs}$ for transit-dependent people.

Based on a focus group study conducted in the Twin Cities metro area, this study explores planning practitioners' views of the potential impacts of AVs on transit under the local context. We are particularly interested in equity, which emphasizes removing systemic barriers to transport and ensuring equitable benefits and costs to transit riders in the $\mathrm{AV}$ era. We aim to answer three research questions:

- What are $\mathrm{AVs}$ ' potential impacts on the transit system?

- What are the implications for equity?

- How should governments and transit agencies prepare for AVs' future impacts? 
Table 1. Focus Group Participants and Affiliations

\begin{tabular}{|l|l|}
\hline Categories & Affiliations \\
\hline Regional government & Metropolitan Council (two representatives from two offices) \\
\hline Urban transit agency & Metro Transit (two representatives from two offices) \\
\hline Suburban transit agency & Southwest Transit \\
\hline County government & Dakota County \\
\hline Local government & City of Minneapolis and City of St. Paul \\
\hline
\end{tabular}

The answers reflect planners' understanding of the potential impacts and associated implications. This reflection is important because these practitioners offer decision-makers support for designing and implementing AV- and transitrelated policies.

\section{Method}

We brought our research questions to transit planners through a two-hour focus group. This qualitative approach provides an environment similar to daily interactions and allows planners to develop their questions according to the conversation flow (Kitzinger 2005). It helps researchers understand not only participants' opinions but also observe how the related topics are being discussed in a social network. This method also reviews participants' in-depth insights from various perspectives without reaching a consensus (Kitzinger 2005; Liamputtong 2011). These merits make focus groups an effective research approach to issues related to $\mathrm{AVs}$.

We invited eight planners from transit agencies and local or regional governments to represent different perspectives of the transport system in the Twin Cities (Table 1). The focus group was held and recorded in November 2018. We applied content analysis to the transcribed conversation and classified the frequency with which certain key concepts appeared in the transcript. We also employed the "scissor-and-sort" technique to analyze the transcript (Stewart, Shamdasani, and Rook 2007). This technique starts with reading through the transcript and identifying sections relevant to the research questions. After coding the relevant materials, we cut and placed pieces together under relevant questions. This approach is widely used in qualitative research and is efficient in grasping and synthesizing useful information.

\section{Findings}

The focus group discussion offered valuable insights to our research questions.

- What are AVs' potential impacts on the transit system?

Regarding challenges, many planners emphasized the instability of government funding. ${ }^{\text {If }}$ shared $\mathrm{AV}$ s become prevalent, the number of personal vehicles sold might decline, which is detrimental to transit agencies that rely on vehicle- 
related revenues (such as vehicle sales tax, registration fees, and parking fees) as funding sources (UTCM, undated). Transit capital funding might also be undermined if shared AVs reduce the federal gasoline tax revenue. Furthermore, transit ridership might decrease if ridesharing and ride-hailing services become more accessible and affordable with the use of personal and shared $\mathrm{AVs}^{2}$

Regarding opportunities, almost all the planners agreed that vehicle automation could offer cost-effective transit operation by reducing labor costs and expanding service hours. ${ }^{3}$ It might improve road conditions and free up road spaces for frequent transit services. ${ }^{4}$ Within the supply constraint, AVs could also improve service flexibility by converting some fixed routes to ondemand services, offering first-mile/last-mile connections, and serving irregular travel schedules. Moreover, AVs could address the lack of licensed drivers with a good credit history in vanpool programs, and hence improve job accessibility and reverse commute to suburban employment, such as the Amazon facility in Shakopee, Minnesota. ${ }^{5}$

Planners also pointed out that $\mathrm{AVs}$ might affect transit drivers. Currently, many transit agencies are facing a driver shortage. The deployment of automated transit would ease the issue. ${ }^{6}$ However, when transit agencies use AVs to deliver ADA paratransit, human employees are still needed, but they would act as support persons, rather than drivers, for riders with disabilities.

- What are the implications for equity issues?

With the decrease in operating cost of automated transit, many planners argued that zero-fare transit might become more feasible. ${ }^{8}$ Despite some concerns over excessive demand related to a free service, many believed that it would relieve the financial burden that may hold back some people from taking transit. Zerofare transit will improve the accessibility of people with low incomes.

Some planners worried about the competition between transit and AVs. The ridership decline could undermine political support for transit services and harm transit-dependent riders. Moreover, the absence of drivers on automated transit might make some riders concerned about safety and security, ${ }^{9}$ which may prevent them from using transit.

- How should governments and transit agencies prepare for AVs' future impacts?

Planners' discussion was centered on four dimensions. First, the development of transit in the advent of $\mathrm{AVs}$ will require a stable and reliable source of funding. Second, it is important to develop new forms of transit services using AV technologies. A consensus was to build dedicated transitways, such as light rail transit (LRT) and bus rapid transit (BRT), which are separated from general traffic. ${ }^{10}$ Dedicated AV transitways could reduce AV-related crashes 
and ease public concerns over the safety of $\mathrm{AV}$ transit. Transit can also serve as a natural testbed for new automated fleet technologies. Third, because unoccupied AVs produce negative externalities (such as congestion and emissions), governments should develop policies to regulate AV use. Finally, transit agencies need to rethink "what it means to be a transit operator, not an elimination of the transit operator," and governments should develop programs that help eliminated drivers find new career paths.

One limitation of this study is that the results are derived from one region in the US. We recommend future studies to expand the discussion to multiple regions to examine the transferability of these results. Although preliminary, this study provides useful findings. Planners thought that transit will still be the backbone of the transport system in the era of $\mathrm{AVs}$ "because it is equitable" as many people do not have travel choices. Planners are open to incorporating AV technologies into the transit system. They acknowledged some potential challenges and opportunities that could arise from the proliferation of AVs. There was a consensus that transport planners and policymakers need to develop policies to ensure the essential role of transit. Furthermore, planners believe that AVs will bring about transit-related equity issues. However, although we emphasized equity to focus group planners, it was still a peripheral topic relative to other topics in the discussion, and few tangible policies pertained to promoting equity. The minimal focus on equity impacts implies that planners have a long way to go before equity becomes a principal consideration in $\mathrm{AV}$-related transit planning. The advent of AVs could be an opportunity to elevate equity in transit planning. However, without proactive planning, AVs may adversely affect the transit system.

\section{Acknowledgment}

This study was funded by the Center for Transportation Studies, University of Minnesota, and supplemented by a grant from the National Science Foundation of the USA (\#1737633).

The following example quotes from the focus group discussion are associated with the statements presented in the manuscript.

1. "Funding, identification of stable funding sources is very important especially in Minnesota (where) a lot of our funding is based on motor vehicle sale taxes.”

2. "and something we hear a lot about is business they like the idea of buses but not really take buses. If that continues to decrease, if people end up using TNC that others can't afford, then who ends up taking transit?” 
3. "opens up a whole bunch of opportunities for serving early/night shifts, evening and weekends that we currently can't serve costeffectively."

4. "And if other vehicles are automated, that means that their needs from the cycle time are reduced and we can potentially increase our phase at the cycle. All of the things go together."

5. "as we try to get people into Vancouver [an exurban employment center], we are finding issues with people having not good enough credit rating, or not licensed, ... improved job accessibility to suburban and exurban job centers, at least from a cost efficiency standpoint.”

6. "We are already experiencing a driver shortage... that speaks to the fact that even level 3 and level 4 once it becomes more affordable, I don't know what kind of impact that might have on driver shortage."

7. "If you think of metro mobility service that driver now no longer has to play the role of driver, they can just play the role of escort."

8. "a pretty viable idea might be 'do we even charge for service anymore?" if operating costs go down so much to where we could still have a lower subsidy than what we're seeing today."

9. "So there's a safety and security piece I think that the driver provides an inherent safety and security piece that could affect our customers' perception of level of service of them."

10. "The most likely targets for any kind of implementation of autonomous vehicles for transit would be transitways service or maybe express freeway services. That would change the way we plan for transitways in the region, at least give us time to rethink priorities and we can provide that service." 


\section{REFERENCES}

Cohen, S., S. Shirazi, and T. Curtis. 2017. Can We Advance Social Equity with Shared, Autonomous and Electric Vehicles? Institute of Transportation Studies at the University of California, Davis.

Cohn, Jesse, Richard Ezike, Jeremy Martin, Kwasi Donkor, Matthew Ridgway, and Melissa Balding. 2019. "Examining the Equity Impacts of Autonomous Vehicles: A Travel Demand Model Approach.” Transportation Research Record 2673 (5): 23-35. https://doi.org/10.1177/ $\underline{0361198119836971 .}$.

Kitzinger, J. 2005. “Focus Group Research: Using Group Dynamics.” Qualitative Research in Health Care 56: 70.

Liamputtong, Pranee. 2011. Focus Group Methodology: Principles and Practice. Sage Publications. https://doi.org/10.4135/9781473957657.

Lutin, Jerome. 2018. "Not If, but When: Autonomous Driving and the Future of Transit.” Journal of Public Transportation 21 (1): 92-103. https://doi.org/10.5038/2375-0901.21.1.10.

Stewart, David W., Prem N. Shamdasani, and Dennis W. Rook. 2007. "Analyzing Focus Group Data." In Focus Groups: Theory and Practice, 20. https://doi.org/10.4135/9781412991841.

UTCM. Undated. A Guide to Transportation Funding Options: Transit Funding. University Transportation Center for Mobility, Texas Transportation Institute, College Station, TX.

Wiseman, Yair. 2018. "In an Era of Autonomous Vehicles, Rails Are Obsolete." International Journal of Control and Automation 11 (2): 151-60. https://doi.org/10.14257/ijca.2018.11.2.13. 